\title{
The Prevalence of Antimicrobial Resistance and Serotypes of Streptococcus pneumoniae in the Kingdom of Bahrain
}

\author{
A. Haifa Al-Muhtaresh and Khalid Mubarak Bindayna* (D) \\ Department of Microbiology, Immunology, and Infectious Diseases, College of Medicine and Medical Sciences, \\ Arabian Gulf University, Manama, Kingdom of Bahrain.
}

\begin{abstract}
Streptococcus pneumoniae (S. pneumoniae), also known as pneumococcus, is found in the upper respiratory tract of $\mathbf{5 - 7 0 \%}$ of healthy people. It causes otitis media, pneumonia and invasive pneumococcal diseases (IPD). The group with the highest risk for pneumococcal diseases are children, elderly people and people with chronic systemic illnesses. The identification of these serotypes is crucial to monitor the prevalent serotypes, to track resistance patterns, and to evaluate the efficacy of treatment and vaccination. Our aim was to determine antibiotic resistance in S. pneumoniae, identify the most common serotypes, determine the association between highly resistant strains and most common serotypes, and select an effective vaccine against the predominant serotypes in the Kingdom of Bahrain. One hundred isolates were included in the study. Antimicrobial susceptibility was determined by agar dilution and serotypes were determined by the Quellung reaction. Antimicrobial resistance rates were highest for penicillin in children $\leq 5$ years old (34\%) and elderly patients (29\%). For the serotypes distribution of S. pneumoniae, the predominant serotypes were 19, 6, 23, 3 and 14 in the different age groups. The predominant serotypes that showed resistance to three antimicrobial agents were 19, 6, 23 and 14. The increasing pneumococcal resistance to penicillin, erythromycin, and tetracycline indicates the need for preventive measures, antibiotics use monitoring and stewarding. In light of the expanding prevalence of $S$. pneumoniae resistant to multiple antimicrobial agents, the need for an effective pneumococcal vaccine has become very important.
\end{abstract}

Keywords: Antimicrobial resistance, Pneumococcal vaccine, Serotypes, Streptococcus pneumoniae

*Correspondence: bindayna@agu.edu.bh; +97317239766

(Received: September 11, 2019; accepted: January 15, 2020)

Citation: A. Haifa Al-Muhtaresh and Khalid Mubarak Bindayna, The Prevalence of Antimicrobial Resistance and Serotypes of Streptococcus pneumoniae in the Kingdom of Bahrain, J. Pure Appl. Microbiol., 2020; 14(1):133-140. https://doi.org/10.22207/ JPAM.14.1.14

(C) The Author(s) 2020. Open Access. This article is distributed under the terms of the Creative Commons Attribution 4.0 International License which permits unrestricted use, sharing, distribution, and reproduction in any medium, provided you give appropriate credit to the original author(s) and the source, provide a link to the Creative Commons license, and indicate if changes were made. 


\section{INTRODUCTION}

Streptococcus pneumoniae also known as pneumococcus, is found in the upper respiratory tract of $5-70 \%$ of healthy people. It causes otitis media, pneumonia, sinusitis and also invasive pneumococcal diseases (IPD) $)^{1,2}$.
The serotypes identification is crucial to monitor the prevalent serotypes, resistance patterns, and to evaluate the efficacy of treatment and vaccination ${ }^{3}$. Serotype distribution in different countries is shown in Table 1.

Table 1. Serotype distribution in different countries ${ }^{4}$

\begin{tabular}{lcccccc}
\hline Serotype & $\begin{array}{c}\text { Canada } \\
(n=15)\end{array}$ & $\begin{array}{c}\text { U.K. } \\
(n=9)\end{array}$ & $\begin{array}{c}\text { Spain } \\
(n=61)\end{array}$ & $\begin{array}{c}\text { Sweden } \\
(n=223)\end{array}$ & $\begin{array}{c}\text { U.S. } \\
(n=46)\end{array}$ & $\begin{array}{c}\text { Total } \\
(n=354)\end{array}$ \\
\hline 1 & & 22 & 2 & 4 & 2 & 3 \\
3 & & 11 & 16 & 6 & 15 & 9 \\
4 & & & & 7 & 11 & 6 \\
5 & & & 2 & $<1$ & 9 & 2 \\
$6 \mathrm{~A}$ & & & & 3 & & 2 \\
$6 \mathrm{~B}$ & & & 2 & 4 & 4 & 3 \\
$7 \mathrm{~F}$ & 13 & & 5 & 10 & 2 & 8 \\
8 & 7 & & 5 & 1 & 2 & 2 \\
$9 \mathrm{~N}$ & & & & 3 & & 2 \\
$9 \mathrm{~V}$ & 7 & 11 & 3 & 13 & 9 & 11 \\
$11 \mathrm{~A}$ & & & 3 & 1 & 2 & 2 \\
$12 \mathrm{~F}$ & & & 5 & $<1$ & 2 & 1 \\
14 & 53 & 22 & 11 & 16 & 7 & 15 \\
$18 \mathrm{C}$ & 7 & 11 & 8 & 1 & 2 & 3 \\
$19 \mathrm{~A}$ & 7 & & 7 & 5 & 2 & 5 \\
19F & & 11 & 7 & 3 & 2 & 3 \\
$22 \mathrm{~F}$ & & & 2 & 4 & 7 & 3 \\
23F & & & 8 & 10 & 11 & 9 \\
Other & 7 & 11 & 15 & 9 & 11 & 10 \\
& & & & & & \\
\hline
\end{tabular}

Note: Blank cells indicate that $<5$ isolate were found.

Although no data on serotypes are available, yet the use of pneumococcal vaccines is common in the Kingdom of Bahrain. This present study was aimed to determine the serotypes and antibiotic susceptibility to penicillin, erythromycin, and tetracycline used for the treatment of pneumococcal infection.

\section{MATERIALS AND METHODS \\ Bacterial isolates}

A total of $100 \mathrm{~S}$. pneumoniae isolates from patients were evaluated after getting an ethical approval from Arabian Gulf University. There were sixty-two isolates from Salmaniya Medical Complex (SMC) and thirty-eight isolates from Bahrain Defence Force Hospital (BDF), that were isolated from inpatients and outpatients with various infections, such as pneumonia, otitis media, sinusitis, conjunctivitis, meningitis, and septicemia. Isolates from blood or cerebrospinal fluid (CSF) were considered invasive, and isolates from upper respiratory tract samples (e.g., ear swab), lower respiratory specimens (e.g., sputum, and deep tracheal aspirates), eye swab, pus, anal swab or wound fluids were considered noninvasive. The demographic data for all patients such as sex, age, and nationality, as well as clinical diagnosis and the sources of the isolates were recorded. All collected strains were taken as subculture isolates from hospital lab on sheep blood agar plates and incubated at $37^{\circ} \mathrm{C}$ for $18-24$ hours in the presence of $5 \% \mathrm{CO}_{2}$. Several colonies of the bacterial culture were then picked, placed in skimmed milk, and stored at $-80^{\circ} \mathrm{C}$ until further testing. The isolates were confirmed as $S$. pneumoniae by positive tests for alpha-hemolysis on blood agar, optochin susceptibility, and bile solubility. 


\section{Study design}

It was a cross sectional study. The Strengthening the Reporting of Observational Studies in Epidemiology (STROBE) guidelines were used.

\section{Antibiotic sensitivity testing}

The dilution of antimicrobial agents was made in $\delta \mathrm{H}_{2} \mathrm{O}$. Two ml of the previous antimicrobial concentration was poured into the Petri dishes. Then $18 \mathrm{ml}$ of Mueller Hinton agar (MHA) with sheep blood was poured into plates. After that, plates to be used were left at room temperature overnight to dry. The colonies were emulsified in Mueller Hinton broth where the suspension optical density was adjusted to 0.5 of McFarland standards. Then $2 \mu \mathrm{l}$ of the colony suspension was inoculated as a spot onto the surface of each agar plate. The S. pneumoniae ATCC 49619 strain was used as quality control for testing. The plates were incubated at $37^{\circ} \mathrm{C}$ in a $\mathrm{CO}_{2}$ incubator for 18-24 hours. The strains and sensitivity testing (MIC) were performed according to Clinical and Laboratory Standards Institute guidelines (CLSI), see Table $2^{5}$.

\section{Serotyping}

Pneumococcal serotypes were determined using the Quellung reaction with the Pneumotest kit which contains 12 pneumococcal
Table 2. Antimicrobial breakpoints for S. pneumoniae

\begin{tabular}{|c|c|c|c|}
\hline \multirow[t]{2}{*}{ Antimicrobial } & \multicolumn{3}{|c|}{ Breakpoints } \\
\hline & $\begin{array}{l}\text { Sensitive } \\
\text { (S) }\end{array}$ & $\begin{array}{l}\text { Intermediate } \\
\text { (I) }\end{array}$ & $\begin{array}{c}\text { Resistance } \\
\text { (R) }\end{array}$ \\
\hline Penicillin & $\mathrm{MIC} \leq 0.06$ & $\mathrm{MIC}=0.122-1$ & $\mathrm{MIC} \geq 2$ \\
\hline Erythromycin & $\mathrm{MIC} \leq 0.25$ & $\mathrm{MIC}=0.5$ & $M I C \geq 1$ \\
\hline Tetracycline & $\mathrm{MIC} \leq 2$ & $\mathrm{MIC}=4$ & $M I C \geq 8$ \\
\hline
\end{tabular}

*Antimicrobial breakpoints (minimum inhibitory concentration MIC $(\mu \mathrm{g} / \mathrm{ml})$ ) for S. pneumoniae based on the guidelines of the Clinical and Laboratory Standard Institute ${ }^{6}$.

pool antisera produced by the Statens Serum Institut, Copenhagen, Denmark ${ }^{7}$.

\section{Statistical analysis}

The chi-square test was used to identify differences in prevalence of antimicrobial resistance. A $p$-value of $<0.05$ was considered significant.

\section{RESULTS}

The demographic data for patients is shown in Table 3. The male-to-female ratio was 1.4:1. Many of the patients were children $\leq 5$ years old (44\%), the next biggest group was of patients $16-64$ years of age (34\%). There was no statically significant difference between the age groups in this study.

Table 3. Antimicrobial resistance of S. pneumonia isolates by age, sex, and site of infection

\begin{tabular}{|c|c|c|c|c|c|c|}
\hline \multirow{2}{*}{$\begin{array}{l}\text { Patient } \\
\text { characteristics }\end{array}$} & \multicolumn{6}{|c|}{ No. (\%) of isolates } \\
\hline & Total & $\begin{array}{l}\text { Resistant to } \\
\text { penicillin }\end{array}$ & $\begin{array}{l}\text { Resistant to } \\
\text { erythromycin }\end{array}$ & $\begin{array}{l}\text { Resistant to } \\
\text { tetracycline }\end{array}$ & Invasive & Noninvasive \\
\hline \multicolumn{7}{|l|}{ Age (yr) } \\
\hline$\leq 5$ & 44 & $15(34)$ & $17(39)$ & $14(32)$ & $10(34)$ & $34(77)$ \\
\hline $6-15$ & 5 & $1(20)$ & $3(60)$ & $3(60)$ & $1(20)$ & $4(80)$ \\
\hline $16-64$ & 34 & $9(26)$ & $11(32)$ & $12(35)$ & $7(21)$ & $27(79)$ \\
\hline$\geq 65$ & 17 & $5(29)$ & $6(35)$ & $5(17)$ & $5(17)$ & $12(71)$ \\
\hline \multicolumn{7}{|l|}{ Sex } \\
\hline Male & 58 & $17(29)$ & $21(36)$ & $19(33)$ & $14(24)$ & $44(76)$ \\
\hline Female & 42 & $13(40)$ & $16(38)$ & $15(36)$ & $9(21)$ & $33(79)$ \\
\hline \multicolumn{7}{|l|}{ Site of infection } \\
\hline Eye & 28 & $7(25)$ & $8(29)$ & $7(25)$ & & \\
\hline Lower respiratory tract & 24 & $8(33)$ & $9(38)$ & $9(38)$ & & \\
\hline Blood & 21 & $4(19)$ & $9(43)$ & $9(43)$ & & \\
\hline Upper respiratory tract & 16 & $8(50)$ & $8(50)$ & $6(38)$ & & \\
\hline Other & 10 & $2(20)$ & $2(20)$ & $2(20)$ & & \\
\hline CSF & 1 & $1(100)$ & $1(100)$ & $1(100)$ & & \\
\hline
\end{tabular}

The predominant serotypes were $19,6,23,3$, and 14 


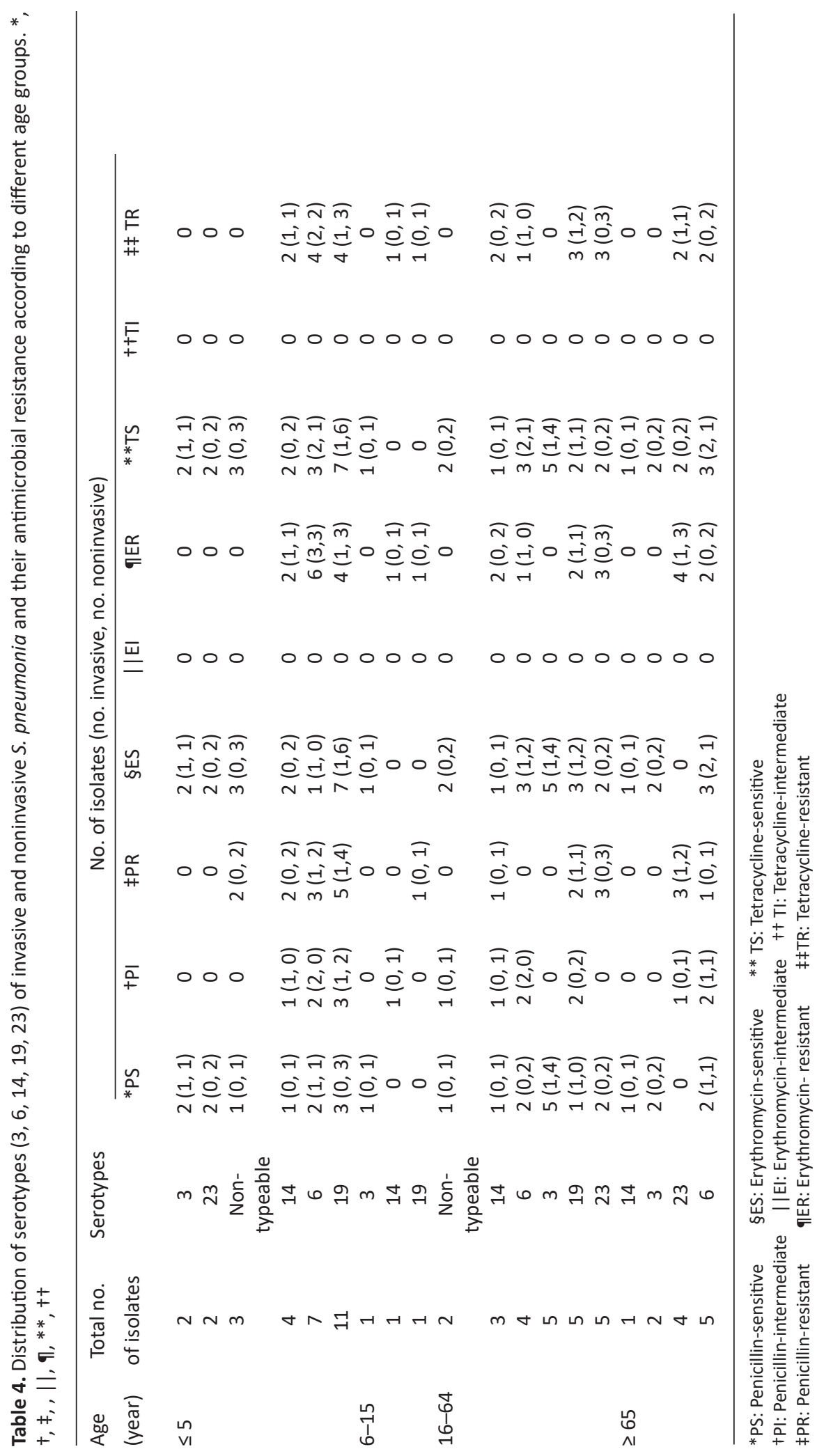


Penicillin resistance was higher among upper respiratory tract than among blood isolates. The 100 pneumococcal isolates were first tested for antimicrobial susceptibility. The sources of the isolates, and their antimicrobial resistance pattern are shown in Table 3. The prevalence of penicillin-resistant isolates in this study was high in children $\leq 5$ years old (34\%) and elderly patients (29\%). For erythromycin resistance, high rates were found in patients between $6-15$ years old $(60 \%)$ with only five isolates which is a very small group and in children $\leq 5$ years old $(39 \%)$. For tetracycline resistance, high prevalence rate was found in the patients between 6-15 years old $(60 \%)$ again with only five isolates which is a very small group and in patients between $16-64$ years old (35\%). There was no significant difference in resistance for any of the antibiotics between the age groups. The prevalence of penicillin resistance among the upper respiratory tract isolates ( 8 of 16) was significantly higher than that among the blood isolates (4 of 21) ( $p=0.046)$. Among the 100 isolates, 39 were sensitive to all the three antibiotics and 26 isolates showed resistance to more than one antibiotic. No differences were found in antibiotics resistance between upper and lower respiratory tract infections. The antibiotics resistance between invasive and noninvasive isolates was also not significantly different.

Of the isolates, 95 (95\%) were serotyped and $5(5 \%)$ were unidentifiable. The predominant serotypes among all patients were the serotypes $19(n=17), 6(n=16), 23(n=11), 3(n=10)$, and 14 $(n=8)$ is shown in Table 4. The distribution of these serotypes were not different between the age groups. The strains with serotypes 19, 23, 6, and 14 were most often resistant to antibiotics, while of the five most common strains the one with serotype 3 was never found to be resistant to antibiotics.

\section{All serotypes of invasive infections in children are included in the vaccines}

The prevalence of S. pneumoniae serotypes in different infections as per the age group in children is shown in Table 5. The PPV23 vaccine given to individuals of ages $>2$ and $<65$ years in high risk groups includes the serotypes $1,2,3,4,5,6 \mathrm{~B}, 7 \mathrm{~F}, 8,9 \mathrm{~N}, 9 \mathrm{~V}, 10 \mathrm{~A}, 11 \mathrm{~A}, 12 \mathrm{~F}, 14$, 15B, 17F, 18C, 19F, 19A, 20, 22F, 23F, and 33F. The serotypes of the isolates of invasive infections observed in children $>2$ years old were covered by the PPV23 vaccine. Also, in the groups of at

Table 5. S. pneumoniae serotypes identified in children and their coverage by pneumococcal vaccines

\begin{tabular}{|c|c|c|c|}
\hline $\begin{array}{l}\text { Age }(y r) \text { and } \\
\text { vaccines }\end{array}$ & $\begin{array}{l}\text { S. pneumoniae isolates } \\
\text { ( } \mathrm{n}=\text { number of strains) }\end{array}$ & $\begin{array}{l}\text { coverage } \\
\text { by vaccine }\end{array}$ & $\begin{array}{l}\text { non-coverage by vaccine (non } \\
\text { covered serotypes) }\end{array}$ \\
\hline \multirow[t]{5}{*}{$\geq 2$, PPV23 } & All $(n=100)$ & $91.4 \%$ & $\begin{array}{l}8.6 \%((16,36,37),(21,39),(24, \\
31,40) \text { and } 3 \text { strains were non-typeable })\end{array}$ \\
\hline & Invasive ( $\mathrm{n}=23$ ) & $100 \%$ & - \\
\hline & Penicillin-resistant $(n=30)$ & $95.2 \%$ & $4.8 \%$ (one strain was non-typeable) \\
\hline & Erythromycin-resistant $(n=37)$ & $100 \%$ & - \\
\hline & Tetracycline-resistant $(n=34)$ & $100 \%$ & - \\
\hline \multirow[t]{5}{*}{$<2$, PCV13 } & All & $66.7 \%$ & $\begin{array}{l}33.3 \%(10,11 \text {, two strains were } \\
15,17,20,22,(24,31,40) \text {, and } \\
\text { two strains were non-typeable) }\end{array}$ \\
\hline & Invasive & $100 \%$ & - \\
\hline & Penicillin-resistant & $77.8 \%$ & $\begin{array}{l}22.2 \% \text { ( } 11 \text { and one strain was } \\
\text { non-typeable) }\end{array}$ \\
\hline & Erythromycin-resistant & $88.9 \%$ & $11.1 \%(20)$ \\
\hline & Tetracycline-resistant & $85.7 \%$ & $14.3 \%(20)$ \\
\hline \multirow[t]{5}{*}{$\begin{array}{l}\geq 2 \text { and }<5 \\
\text { PCV13 }\end{array}$} & All & $69 \%$ & $\begin{array}{l}31 \%(10,11, \text { three strains were } \\
15,17,20,22,(21,39),(24,31, \\
40) \text { and three strains were non-typeable) }\end{array}$ \\
\hline & Invasive & $100 \%$ & - \\
\hline & Penicillin-resistant & $78.6 \%$ & $21.4 \%$ (11 and two strains were non-typeable) \\
\hline & Erythromycin-resistant & $87.5 \%$ & $12.5 \%(15$ and 20$)$ \\
\hline & Tetracycline-resistant & $84.6 \%$ & $15.4 \%(15$ and 20$)$ \\
\hline
\end{tabular}


risk children below 2 , and healthy children up to 5 years old, the vaccine PCV13, that includes the serotypes $1,3,4,5,6 \mathrm{~A}, 6 \mathrm{~B}, 7 \mathrm{~F}, 9 \mathrm{~V}, 14,18 \mathrm{C}$, $19 \mathrm{~A}, 19 \mathrm{~F}$, and $23 \mathrm{~F}$ covered all of the serotypes causing invasive infections in these children. PPV23 covered also the serotypes that were antibiotic resistant. The vaccine coverage of nontypeable strains are not known.

Table 6. Common serotypes in all age groups

\begin{tabular}{lc}
\hline Serotypes & Total number of isolates $(\mathrm{n})$ \\
\hline 14 & 9 \\
3 & 10 \\
23 & 11 \\
6 & 16 \\
19 & 17 \\
\hline
\end{tabular}

\section{DISCUSSION}

This is the first study of the kind in the Kingdom of Bahrain to determine S. pneumoniae serotypes. The most common serotypes in all age groups were 19, 6, 23, 3 and 14 which is shown in Table 6.

Similar results were reported in a Saudi Arabian study in the period between 2000 to $2001^{8}$, in Kuwait ${ }^{9}$, Oman $^{10}$, and Turkey ${ }^{11}$. In contrast, different predominant serotypes were found in some European countries such as Denmark like 1, 4, 14, 6A + 6B, 7F, 9V, 3, 12F, and $8^{12}$ and Germany like 19F, 23F, and $6 \mathrm{~B}^{13}$.

This study is different from ones conducted in the Kingdom of Saudi Arabia ${ }^{14}$ and Kuwait ${ }^{9}$, where the most common serotypes were 6, 19, 1 and 3. Similar results to the current study were obtained in Burkina Faso ${ }^{15}$ as well as in England and Wales ${ }^{16}$ for the serotypes 6, 19, 1 and 3. The same study in England and Wales gave a different result for the serotypes $(14,9,4,23$, 3, 12 and 18). Serotypes 19, 23, 3, 6 and 14 were the predominant serotypes among the noninvasive isolates in all age groups in our study. Similar results were found for some serotypes ( 3 and $6 \mathrm{~A}$ ) in the Kingdom of Saudi Arabia ${ }^{14}$, Kuwait (23F, 19F, $6 \mathrm{~A}, 6 \mathrm{~B}$ and 14$)^{9}$ and a study done in Thailand (2007) reported similar serotypes $(19,6 \text { and } 23)^{17}$.

The prevalence of penicillin-resistant isolates in this study was high in children $\leq 5$ years old $(34 \%)$ and in elderly patients (29\%). Similar results were found in studies from Kuwait ${ }^{9}$, US $^{18}$, and Caledonia ${ }^{19}$. For erythromycin resistance, the highest rates were found in patients between
$6-15$ years old $(60 \%)$ and in children $\leq 5$ years old (39\%). This is similar to the result from US ${ }^{20}$ but different from results reported in Thailand (2005), where more resistant isolates were seen in the age group $<6$ years (37.9\%) and between 15-60 years old $(27.5 \%)^{21}$. For tetracycline resistance, the highest prevalence rates were found in the patients between 6-15 years old (60\%) and in patients between 16-64 years old (35\%). In Spain, a similar finding was reported for the adults ${ }^{22}$.

According to the site of infection, in this study, the highest prevalence rate for penicillinand erythromycin-resistant strains were found in upper respiratory tract isolates, similar result for penicillin were reported in Kuwait ${ }^{9}$ and US $^{18}$. Another study from Saudi Arabia in $2004^{14}$, $\operatorname{Iran}^{23}$, and Taiwan ${ }^{24}$ showed highest resistance rates in blood and CSF isolates. But those studies were different from the current one because highest prevalence was found in blood and CSF isolates. For tetracycline resistance, the highest prevalence was found in blood, which is different from $U A E^{25}$ where the highest rate was seen in lower respiratory tract isolates. This study also found that invasive infections were found mainly in the group of children $\leq 5$ years old (34\%). Similar findings were reported in the Kingdom of Saudi Arabia ${ }^{8}$, Kuwait $^{9}$, and Spain ${ }^{22}$.

When looking at antibiotic resistant strains, resistance was most commonly found for the three antibiotics in the serotypes 19, 6, 23 and 14. In Kuwait, a study was conducted in which similar results were obtained for penicillinresistant serotypes $(23 \mathrm{~F}, 19 \mathrm{~F}, 6 \mathrm{~B} \text { and } 14)^{9}$. On the other hand, in the Kingdom of Saudi Arabia, a study showed that the main serotypes among the multidrug-resistant isolates were $19 \mathrm{~F}, 23 \mathrm{~F}$ and $6 A^{14}$. In Turkey ${ }^{11}$ and South Africa ${ }^{26}$, also comparable researches were performed. The most frequently encountered serotypes were 6, 19, 1, 23, and 14 in Turkey and 6, 19, 14, and 23 in South Africa.

In the Kingdom of Bahrain, the 7-valent conjugate vaccine, which includes serotypes $4,6 \mathrm{~B}$, $9 \mathrm{~V}, 14,18 \mathrm{C}, 19 \mathrm{~F}$ and $23 \mathrm{~F}$, was used to cover the strains that cause most invasive pneumococcal diseases in children. Recently, 13-valent conjugate vaccine, which includes $1,3,4,5,6 \mathrm{~A}, 6 \mathrm{~B}, 7 \mathrm{~F}, 9 \mathrm{~V}$, 14, 18C, 19A, 19F and 23F, was introduced to cover more pneumococcal serotypes. Also, the 23-valent 
polysaccharide vaccine (PPV23) is available in the Kingdom of Bahrain for high-risk groups such as HIV positive individuals, sickle cell disease patients and elderly above 65 years old. This study demonstrated that PPV23 had an excellent coverage $(91.4 \%)$ for all strains, with even $100 \%$ coverage for invasive, erythromycin resistant, and tetracycline resistant isolates and high coverage (95.2\%) for penicillin-resistant isolates for children $\geq 2$ years old. Our results demonstrated higher coverage rates by PPV23 for invasive and penicillinresistant strains than in Kuwait (76 to $82 \%)^{7}$. Also, high coverage was reported in South Africa $(97.4 \%)^{26}$ and Uruguay $(96.1 \%)^{27}$.

For PCV13 coverage for children $<2$ years old, the vaccine showed good coverage rates for all serotypes (66.7\%), penicillin-resistant $(77.8 \%)$, erythromycin-resistant $(88.9 \%)$, tetracyclineresistant $(85.7 \%)$ and excellent coverage rate for invasive isolates (100\%). High coverage rate demonstrated in the study from Chile which showed coverage rate of (80\%) for all serotypes ${ }^{28}$. On the other hand, this present study reported higher coverage rate for invasive isolates than another study in Spain $(77.9 \%)^{29}$ and Thailand $(85.7 \%)^{30}$. For children $<5$ years old, this study showed coverage rates of (69\%) for all serotypes, $(100 \%)$ for invasive isolates and $(78.6 \%),(87.5 \%)$, $(84.6 \%)$ for penicillin-, erythromycin-, and tetracycline-resistant isolates, respectively. On the other hand, high coverage rate was demonstrated in a study from China (87.8\%) for all serotypes ${ }^{31}$. In Thailand ${ }^{30}$, lower coverage rates was reported for IPD, it was (87.8\%).

In conclusion, in light of the increasing prevalence of $S$. pneumoniae resistant to multiple antimicrobial agents, the local policies and the immunization should consider these changes and adapt accordingly.

\section{ACKNOWLEDGMENTS}

We thank all the staff at the department of Microbiology, Immunology and Infectious Diseases, College of Medicine and Medical Sciences, Arabian Gulf University for their support.

\section{CONFLICT OF INTEREST}

The authors declare that there is no conflict of interest.

\section{FUNDING}

The King Abdullah Scholarship Program. (Grant No. 20071284).

\section{AUTHORS' CONTRIBUTION}

HAM and KMB designed the experiments. HAM performed the experiments. HAM and KMB analyzed the data and HAM wrote the manuscript. KMB supervised and reviewed the manuscript. HAM and KMB approved the manuscript.

\section{DATA AVAILABILITY}

All datasets generated or analyzed in this research are included in the manuscript.

\section{ETHICS STATEMENT}

Informal consent was taken before the study from each patient. Study approval was issued and maintained by the ethical committee from Arabian Gulf University, Manama, Bahrain before starting the project.

\section{REFERENCES}

1. Obaro S, Adegbola R. The pneumococcus: carriage, disease and conjugate vaccines. J. Med. Microbiol., 2002; 51(2): 98-104. https://doi.org/10.1099/00221317-51-2-98

2. Greenwood D, Richard S, Peutherer J, Barer M. Medical Microbiology: Churchill Livingstone Elsevier; 2007.

3. Goldman E, Green LH. Practicle Handbook of Microbiology, 2009. https://doi.org/10.1201/ 9781420009330

4. Henriques B, Kalin M, Ortqvist A, Olsson Liljequist B, Almela M, Marrie TJ, Mufson MA, Torres A, Woodhead MA, Svenson SB, Kallenius G. Molecular epidemiology of Streptococcus pneumoniae causing invasive disease in 5 countries. J. Infect. Dis., 2000; 182(3): 833-9. https://doi.org/10.1086/315761

5. Schwalbe R, Steele-Moore L, Goodwin A. Antimicrobial susceptibility testing protocols: CRC Press, 2007; 432 p. https://doi.org/10.1201/9781420014495

6. CLSI. M45: Methods for antimicrobial dilution and disk suceptibility testing of infrequently isolated or fastidious bacteria; proposed guideline. US: Clinical and Labratory Standard Institute, Wayne, PA; 2006.

7. Sorensen UB. Typing of pneumococci by using 12 pooled antisera. J. Clin. Microbiol., 1993; 31(8): 2097-100. https://doi.org/10.1128/JCM.31.8.20972100.1993

8. Twum-Danso K, Al-Mazrou AM, Kambal AM, Al-Zamil FA. Penicillin resistance in serogroups/serotypes of S. pneumoniae causing invasive infections in Central Saudi Arabia. Saudi Med. J., 2003; 24(11): 1210-3.

9. Mokaddas EM, Rotimi VO, Albert MJ. Implications of Streptococcus pneumoniae penicillin resistance and serotype distribution in Kuwait for disease treatment 
and prevention. Clin. Vaccine Immunol., 2008; 15(2): 203-7. https://doi.org/10.1128/CVI.00277-07

10. AL-Yaqoubi MM, \& Elhag, K M. Serotype prevalence of penicillin-susceptibility of Streptococcus pneumoniae in Oman. Oman Medical Journal, 2011; 26(1): 43-7. https://doi.org/10.5001/omj.2011.11

11. Aslan G, Emekdas G, Bayer M, Serin MS, Kuyucu N, Kanik A. Serotype distribution of Streptococcus pneumoniae strains in the nasopharynx of healthy Turkish children. Indian J. Med. Res., 2007; 125(4): 582-7.

12. Nielsen SV, Henrichsen J. Incidence of invasive pneumococcal disease and distribution of capsular types of pneumococci in Denmark, 1989-94. Epidemiol Infect., 1996; 117(3): 411-6. https://doi.org/10.1017/ S0950268800059057

13. Reinert RR, Reinert $\mathrm{S}$, van der Linden M, Cil MY, AlLahham A, Appelbaum P. Antimicrobial susceptibility of Streptococcus pneumoniae in eight European countries from 2001 to 2003. Antimicrob Agents Chemother., 2005; 49(7): 2903-13. https://doi.org/10.1128/ AAC.49.7.2903-2913.2005

14. Memish ZA, Balkhy HH, Shibl AM, Barrozo CP, Gray GC. Streptococcus pneumoniae in Saudi Arabia: antibiotic resistance and serotypes of recent clinical isolates. Int. J Antimicrob Agents, 2004; 23(1): 32-8. https:// doi.org/10.1016/j.ijantimicag.2003.05.008

15. Bere LC, Simpore J, Karou SD, Zeba B, Bere AP, Bannerman E, Bille J, Dosso M. Antimicrobial resistance and serotype distribution of Streptococcus pneumoniae strains causing childhood infection in Burkina Faso. Pak. J. Biol. Sci., 2009; 12(18): 1282-6. https://doi.org/10.3923/pjbs.2009.1282.1286

16. Sleeman K, Knox K, George R, Miller E, Waight $P$, Griffiths D, Efstratiou A, Broughton K, Mayon-White RT, Moxon ER, Crook DW. Invasive pneumococcal disease in England and Wales: vaccination implications. J. Infect. Dis., 2001; 183(2): 239-46. https://doi. org/10.1086/317924

17. Srifeungfung S, Chokephaibulkit K, Tribuddharat C. Serotypes and antimicrobial susceptibilities of Streptococcus pneumoniae isolated from hospitalized patients in Thailand. Southeast Asian J. Trop. Med. Public Health, 2007; 38(3): 469-77.

18. Doern GV. Antimicrobial resistance with Streptococcus pneumoniae in the United States. Semin Respir. Crit. Care Med., 2000; 21(4): 273-84. https://doi. org $/ 10.1055 / \mathrm{s}-2000-9863$

19. Michel N, Watson M, Baumann F, Perolat P, Garin B. Distribution of Streptococcus pneumoniae serotypes responsible for penicillin resistance and the potential role of new conjugate vaccines in New Caledonia. J. Clin. Microbiol., 2005; 43(12): 6060-3. https://doi. org/10.1128/JCM.43.12.6060-6063.2005

20. Brown SD, Farrell DJ. Antibacterial susceptibility among Streptococcus pneumoniae isolated from paediatric and adult patients as part of the PROTEKT US study in 2001-2002. J. Antimicrob. Chemother., 2004; 54(Suppl 1): i23-9. https://doi.org/10.1093/jac/dkh311

21. Dejsirilert S, Tienkrim S, Ubonyaem N, Sawanpanyalert P, Aswapokee N, Suankratay C. National antimicrobial resistance surveillance among clinical isolates of Streptococcus pneumoniae in Thailand. J. Med. Assoc. Thai., 2009; 92(Suppl 4): S19-33.

22. Garcia-Suarez Mdel M, Villaverde R, Caldevilla AF, Mendez FJ, Vazquez F. Serotype distribution and antimicrobial resistance of invasive and non-invasive pneumococccal isolates in Asturias, Spain. Jpn. J. Infect Dis., 2006; 59(5): 299-05.

23. Kohanteb J, Sadeghi E. Penicillin-resistant Streptococcus pneumoniae in Iran. Med. Princ. Pract., 2007; 16(1): 29-33. https://doi.org/10.1159/000096137

24. Hsueh PR, Luh KT. Antimicrobial resistance in Streptococcus pneumoniae, Taiwan. Emerg Infect Dis., 2002; 8(12): 1487-91. https://doi.org/10.3201/ eid0812.020178

25. Senok A, Al-Zarouni M, Al-Najjar J, Nublusi A, Panigrahi D. Antimicrobial resistance among Streptococcus pneumoniae and Haemophilus influenzae isolates in the United Arab Emirates: 2004-2006. J. Infect. Dev. Ctries., 2007; 1(3): 296-302. https://doi.org/10.3855/ jidc. 367

26. Klugman KP, Koornhof HJ. Drug resistance patterns and serogroups or serotypes of pneumococcal isolates from cerebrospinal fluid or blood, 1979-1986. J. Infect. Dis., 1988; 158(5): 956-64. https://doi.org/10.1093/ infdis/158.5.956

27. Hortal M, Camou T, Palacio R, Dibarboure H, Garcia A. Ten-year review of invasive pneumococcal diseases in children and adults from Uruguay: clinical spectrum, serotypes, and antimicrobial resistance. Int. J. Infect. Dis., 2000; 4(2): 91-5. https://doi.org/10.1016/S12019712(00)90100-0

28. Inostroza J, Illesca V, Reydet P, Vinet AM, Ossa G, Munoz S, Thompson T, Sorensen RU. Ten-year surveillance of pneumococcal infections in Temuco, Chile: implications for vaccination strategies. Clin. Vaccine Immunol., 2007; 14(6): 660-4. https://doi. org/10.1128/CVI.00379-06

29. Salleras L, Dominguez A, Ciruela P, Izquierdo C, Navas E, Torner N, Borras E. Changes in serotypes causing invasive pneumococcal disease (2005-2007 vs. 1997-1999) in children under 2 years of age in a population with intermediate coverage of the 7-valent pneumococcal conjugated vaccine. Clin. Microbiol. Infect., 2009; 15(11): 997-1001. https:// doi.org/10.1111/j.1469-0691.2009.02938.x

30. Phongsamart W, Srifeungfung S, Dejsirilert S, Chatsuwan T, Nunthapisud P, Treerauthaweeraphong $V$, Rungnobhakhun $\mathrm{P}$, Chokephaibulkit K. Serotype distribution and antimicrobial susceptibility of $\mathrm{S}$. pneumoniae causing invasive disease in Thai children younger than 5 years old, 2000-2005. Vaccine, 2007; 25(7): 1275-80. https://doi.org/10.1016/j. vaccine.2006.10.001

31. Xue L, Yao K, Xie $G$, Zheng $Y$, Wang $C$, Shang $Y$, Wang H, Wan L, Liu L, Li C, Ji W, Xu X, Wang Y, Xu P, Liu Z, Yu S, Yang Y. Serotype distribution and antimicrobial resistance of $S$. pneumoniae isolates that cause invasive disease among Chinese children. Clin. Infect. Dis., 50(5): 741-4. https://doi.org/10.1086/650534 